$(200)$

TL7

$\bullet$

Geology and Mineralogy

Instrumentation

This document consists of 26 pages, including; page $2 a$ 。

Series A

UNITED STATES DEPARTMENT OF THE INTERIOR

GEOLOGICAL SURVEY

PORTABLE SCINTILLATION COUNTERS FOR GEOLOGIC USE*

By

E. E. Wilson, V。C。 Rhoden, W. W. Vaughn, and Henry Faul

December 1953

Trace Elements Investigations Report 403

This preliminary report is distributed without editorial and technical review for conformity with official standards and nomenclature. It is not for public inspection or quotation.

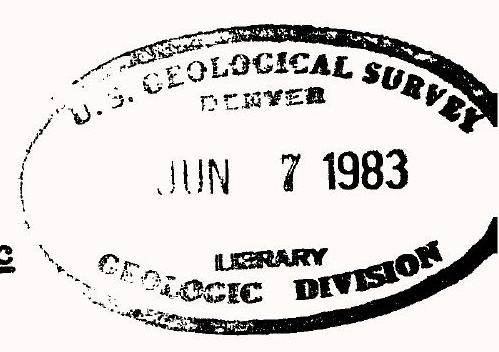

*This report concerns work done on behalf of the Division of Raw Materials of the U.S. Atomic Energy Commission. 
USGS-TEI -403

\section{GEOLOGY AND MINERRALOGY}

\section{INSTRUMENTATION}

Distribution (Series_A)

No. of copies

Argonne National Laboratory .......... . 。 . . 1

Atomic Energy Commission, Washington ......... . 2

Battelle Memorial Institute, Columbus .....。. . . . 1

Carbide and Carbon Chemicals Company, Y-12 Area 。. . . . . 1

Division of Raw Materials, Albuquerque. . . . 。 。 。 . 1

Division of Raw Materials, Butte. . . . . . . . . . . I

Division of Raw Materials, Denver ....。. . . 。 . 。 1

Division of Raw Materials, Douglas. ............ 1

Division of Raw Materials, Hot Springs。. . . . . . . . . 1

Division of Raw Materials, Ishpeming. ........... 1

Division of Raw Materials, Phoenix. .......... 1

Division of Raw Materials, Richfield............ 1

Division of Raw Materials, Salt Lake City . . . . 。 . 。 1

Division of Raw Materials, Washington ........... 3

Dow Chemical Company, Pittsburg .........。。。. 1

Exploration Division, Grand Junction Operations Office。 ... 6

Grand Junction Operations Office............. 1

National Lead Company, Winchester .... . . . . . . . . 1

Technical Information Service, Oak Ridge。 . . . . . . 6

Tennessee Valley Authority, Wilson Dam。 ......。... - 1

U. S. Geolegical Survey:

Alaskan Geology Branch, Menlo Park。 ... . . . . . 1

Fuels Branch, Washington. ..........。。 1

Geochemistry and Petrology Branch, Washington ....... 1

Geophysics Branch, Washington ............ 20

Mineral Deposits Branch, Washington ........... 2

E。H.Bailey, Menlo Park 。............... 1

A。 L。 Brokaw, Grand Junction. ............. 2

K. L. Buck, Denver................... 2

J.R. Cooper, Denver。... ............... 1

N。M。 Denson, Denver. . . ............ 1

C。 E。 Dutton, Madison . . . . . ........ 1

W. L. Emerick, Plant City 。.........。.... 1

L。S. Gardner, Albuquerque . . ... . . . . . . . 1

M。 R。 Klepper, Washington ............... 1

A. H。 Koschmann, Denver ............... 1

R. A. Laurence, Knoxvilie ............... I

D. $M_{0}$ Lemmon, Washington。

J。 D。 Love, Laramie ................. 1

V。 E。 McKelvey, Menlo Park。 o. . . . . . . 。 . 1

R. JoRoberts, Salt Lake City ...........。. 1

Q. Do Singewald, Beltsrille .............. 1

J。 F。 Smith, Jro, Denver. ....... 。 . . 。 . . 1

A. E. Weissenborn, Spokane. . . 。 。 . . 。 。 。 1

TEPCO, Denver 。. . ................ 2

TEPCO, RPS, Washington, (Including master). ...... $\frac{10}{90}$ 
CONTENTS

Page

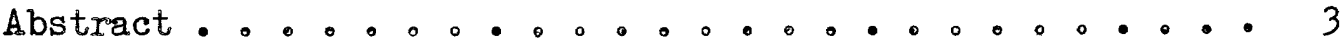

Introduction . $. . . .0 .0 .0 . . . . . . .3$

Physical design。 . . . . . . . . . . . . . . . 5

Electronic design . . . . . . . . . . . . . . . 7

Calibration . . . . . . . . . . . . . . . . . . o 13

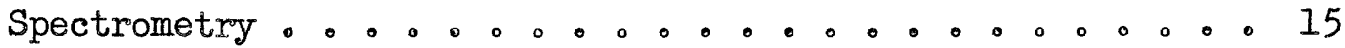

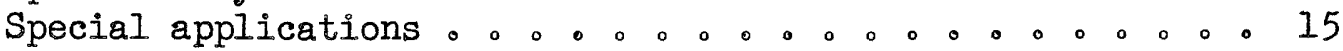

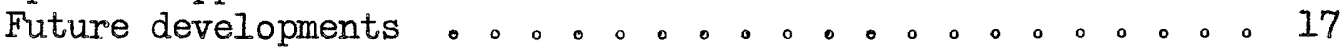

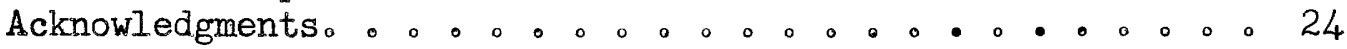

Literature cited o. 0.000 .000 .000 .00 .00024

\section{ILLUSTRATIONS}

Figure 1. Three commercially available versions of the

scintillation counter o. . . . ..。. 6

2. The crystal photomultiplier assembly - . . . 8

3. Circuit diagram of the portable scintillation

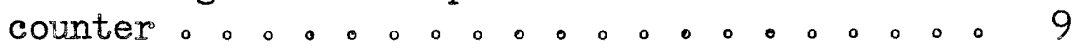

40 Carmounted twin scintillation heads, shielded with lead for directional search . . . . 16

5. Scintillation logging equipment 。. . . . 18

6. Matching circuit for transmission of pulses over long coaxial cables . . . . . . . . 19

7. Experimental model of the integrating (total inten sity) scintillation counter ....... 20

8. Circuit diagram of the integrating scintillation counter o. . . . . . . . . . . . 22 
PORTABLE SCINTILUATION COUNTERS FOR GEOLOGIC USE

By E.E。 Wilson, V.C。Rhoden, W。W, Vaughn, Henry Faul

ABSTRACT

A small, light, portable scintillation counter, primarily intended for geologic field use, has been designed and is now commercially manufactured. The instrument embodies a very fast trigger-amplifier and a compact relaxation-oscillator power supply. The circuit takes full advantage of the high counting rate that can be obtained from a sodium iodide crystal. Another, still smaller and lighter, scintillation counter of the total intensity tzpe is now being tested.

\section{INTRODUCTION}

From rather clumsy beginnings (Rajewsky, 1943; Ridland, 1945), the portable gamma-ray detector has rapidly developed into a popular geologic tool. It is probably true that there are more gamma-ray detectors in use today than all other geophysical instruments.

The Nenhattan Engineer District expended considerable effort on the design of a portable Geiger-rofler survey meter for health physics work. The basic design adopted toward the end of the war utilized the Schmitt (1938) trigger circuit as an amplifier, with various high voltage supplies (dry batteries, oscillators, vibrators), and was produced commercially by a number of instrument manufacturers. The instrument was clearly successful and continues to be manufactured to this day without major modifications. In spite of the fact that this instrument was designed primarily for use in health physies work indoors, it has found wide 
acceptance in geologic field application (Faul, 1948, 1950).

With increasing experience in radiation measurement for geo: ogical applications, it became more and more apparent that the ordinary survey meter did not have sufficient sensitivity to be useful in studies where one was dealing with low activities, roughly of the order of background radiation. Iarge G-M tubes were connected to the survey meter, singly or in bundles, and it was found that with such arrangements it was possible to obtain data of great geologic significance (Nelson, 1953; Slack, 1949; Slack and Whitham, 1959; and unpublished reports). However, the large counters (up to 40 inches long) had one great disadvantage: they were exceedingly clumsy to use in the field.

A portable scintillation counter would not be subject to this handicap. Such an instrument was announced by Brownell in Canada (1950), and became commercially available shortly thereafter. The Canadian instrument was relatively large and heavy (about 15 lbs.), had considerable drift with temperature and time, and was very costly (over $\$ 1,000$ in the U.S.) so that it could not become widely used. Nevertheless, Brownell's work showed that the scintillation counter could be very useful in geologic studies.

About 1950, portable scintillation counters were developed independently at the Oak Ridge National Iaboratory and Los Alamos Scientific Iaboratory. Each of these instruments had definite advantages: the Cak Ridge circuit (Borkowsky and DandI, private comm.) was very fast and had a good oscillator power supply; the Los Alamos circuit (Watts, private corm.) was built with subminiature tubes and could be made very small and light. Obviously, an instrument combining the 
advantages of both designs would be of great value to the geologic profession, and we decided to undertake this development.

The instrument that was developed (fig. 1) weighs about 7 pounds, stands about 12 inches high, and retails for about $\$ 500$. It has now been produced in quantity by three manufacturers and extensively used during the 1953 field season by many pritate individuals and personnel of the U.S. Geological Survey, the U.S. Atomic Energy Commission and the U.S. Department of Agriculture. Mich remains to be learned about the calibration and optimum energy response of scintillation counters for field use, but there is no doubt that, in spite of their serious limitations, they are of great value to the geologist.

\section{PHYSICAL DESIGN}

The outward design of the instrument was determined largely by a committee of field geologists in Denver, under the choirmanship of I. R. Page of the Geological Survey. It was decided that the instrument should be housed in two boxes, of which one would contain little more than the batteries, or roughly half the weight of the device. The battery box has suitable loops so that it can be worn on the belt, and is connected to the probe by a flexille coiled cord.

The proke contains most of the circuitry, the sensitive element, and the meter. It must be as light as possible, and waterproof for work in mines. For obvious reasons, the probe must be very rugged. The meter must be placed to be easily readable at arm's length, and the use of the instrument should require only one hand. The probe fastens to the bettery case with a spring catch and must be firmly held, yet easily removed. 


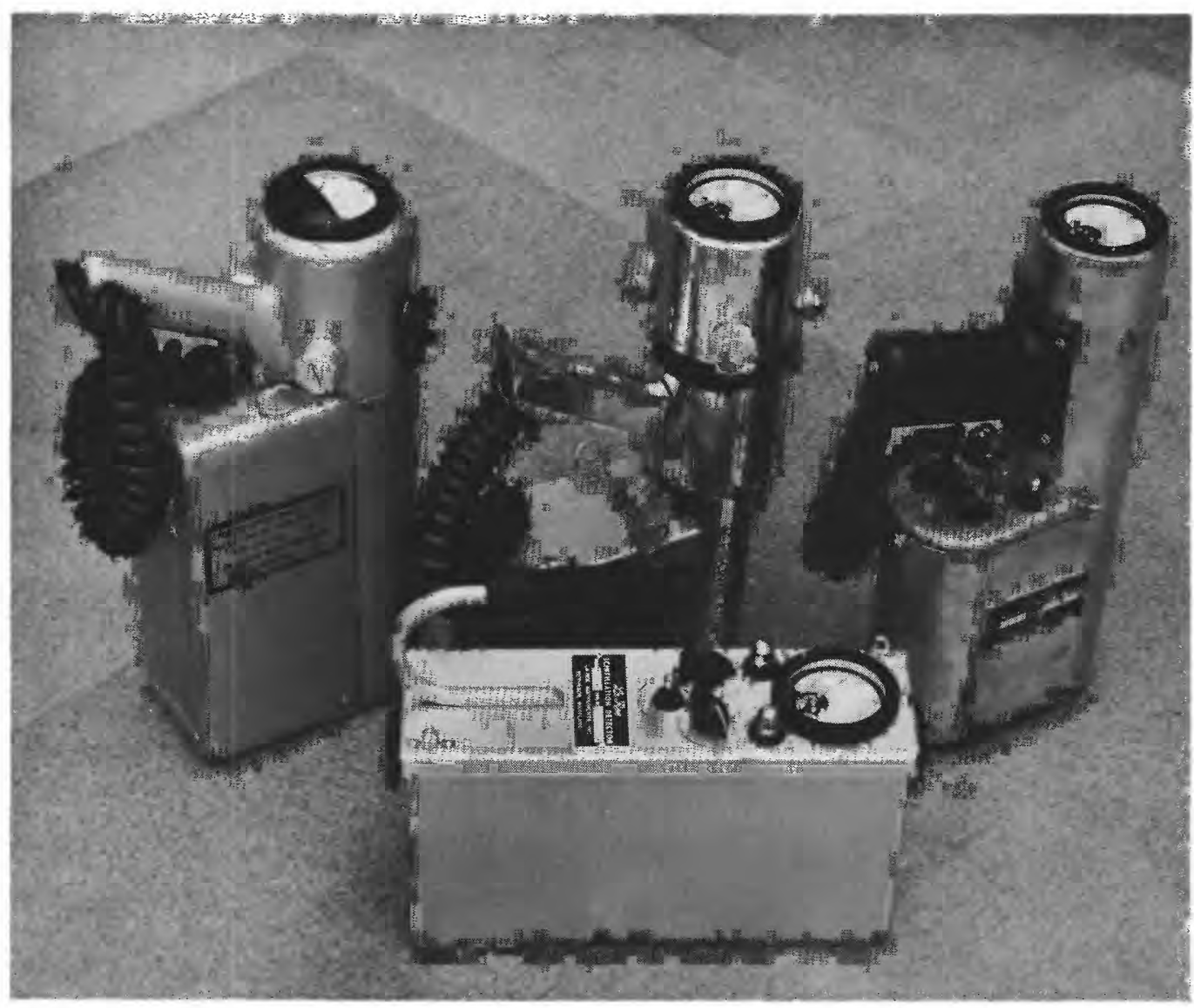

Figure 1. Three commercially available versions of the portable scintillation counter 
The sensitive element is a very fragile assembiy and must be mounted in the probe with utmost care to prevent datiage in normal (i,e., rather rough) use. The thallium-actirated sodium iodide rystal, about one cubic inch or larger in volume, is housed in a thin spur-aluminum can (fig. 2) filied with ciear silicone fiuid of very nigh viscosity (as much as severai hundred thousand centistokes). The can slips over the erd of the photomultiplier and is attached with industrial adhesive tape. A phosphor bronze spring $x \in e p s$ the polished face of the crystal in coritact wis the photocathod. The otrer surfeces of the crystal are left rough. Urercially available potted crystals are preferred by one manufecturer, but the silicone rount originally developed at the Chalk River Iaboratury (Carmichael, private comm.) is less costiy and mechanically sturdict, We have not observed any detrimental reaction between the erystal, tric tape, and the sificone oil. The photomultiplier is magneticaliy stijolded by a thin sheet of highly permeable nickei-iron alloy such as is available commercially under various trade rames. The entire assembiy of the sensitivo eicment is suspended in the probe in sponge rubber, to minimize damage when the probe is dropred accidentally,

\section{ELECTRCNIC DESIGN}

The 1 Is ampitfier (fig. 3) is a trigger pair of sub-miniature tubes ( tyFe $(\mathrm{N}-533 \mathrm{M}$ ) with $\mathrm{V}-1$ normally conducting. The input sensitivity is variable by reans of the potentiometer marked "CALIBRATE", which directly affects the bias on $\mathrm{V}-2$ and to some extent, the bias or $\mathrm{V}-1$, and is adjustable down to a few millivolts, or a point just above the dark current of the photomultiplier tube. The amplifier has a gain of 


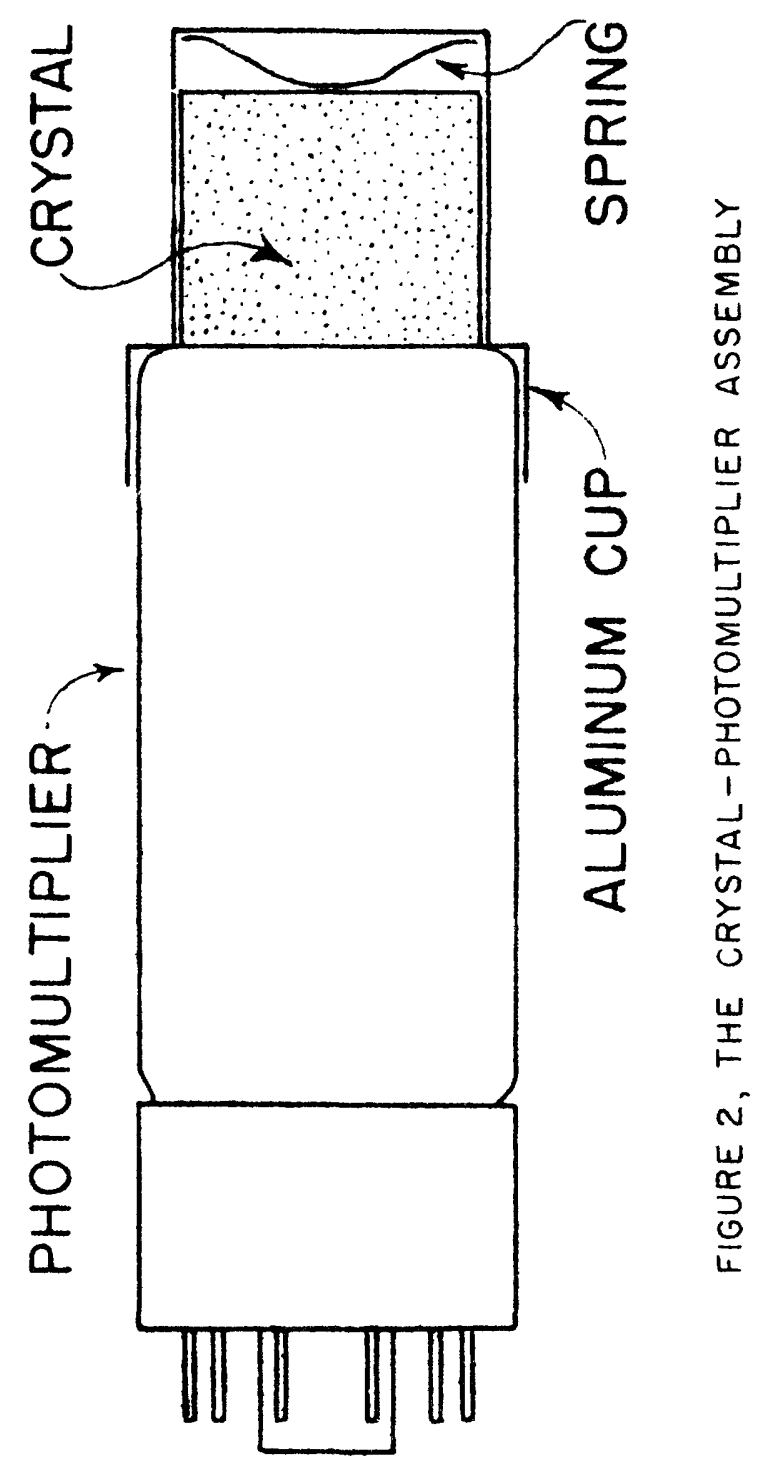




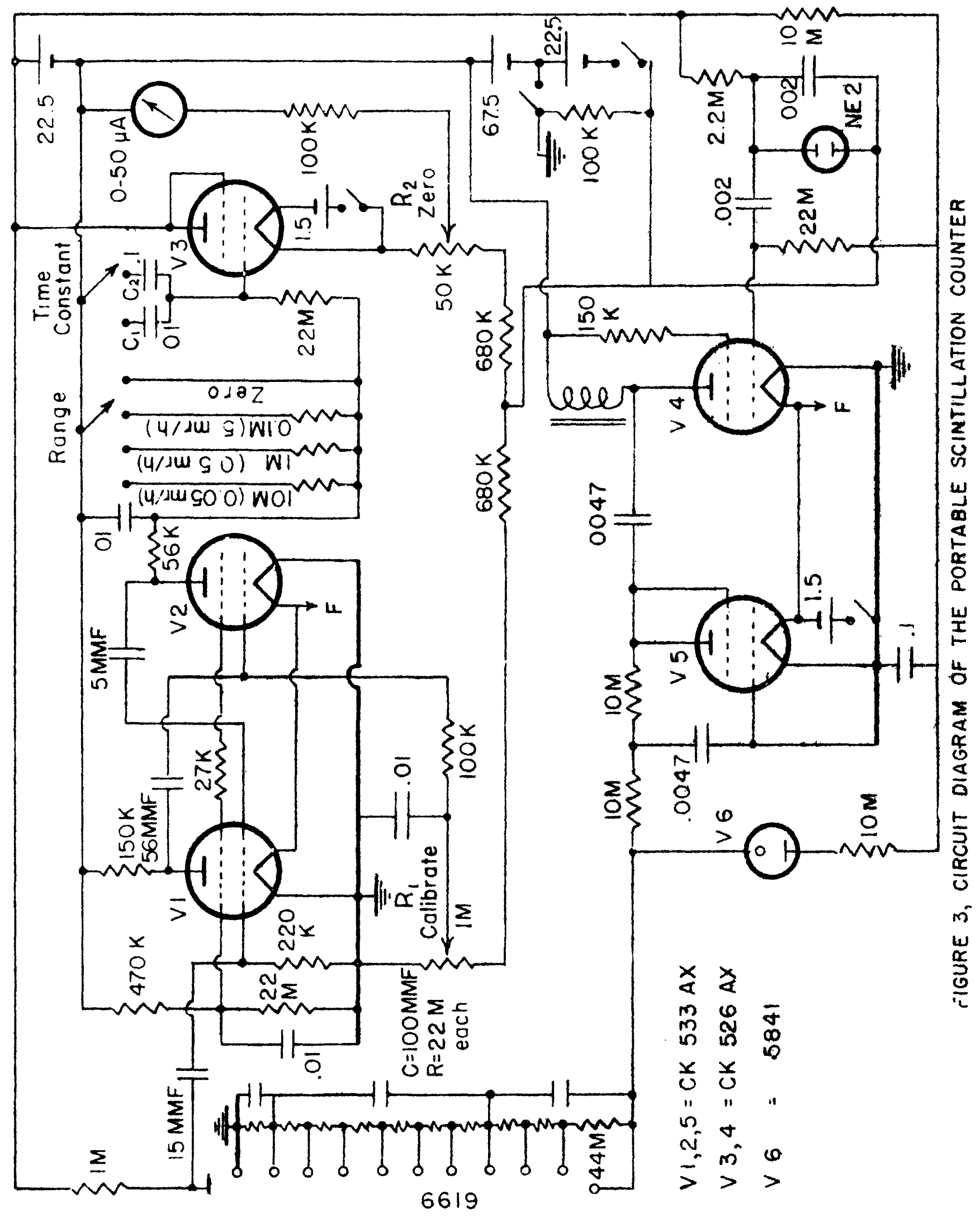


20, a pulse length of 6 microseconds and a 14 microsecond resolution period. The pulse length and resolution period are independent of range setting, and less dependent on input pulse amplitude and counting rate than any other type amplifier tested for portable scintillation counters. Specifications call for a minimum rate of 150,000 counts per minute in a field of one milliroentgen per hour of radium gamma rays with a cylindrical crystal one inch thick and lit inches in diameter. The ranges are selected by switching resistors in the plate circuit of V-2. A series network with pre-selected values for the range settings was tried and was very satisfactory, but procurement of resistors of the correct values for quantity production proved to be difficult. The present method was chosen as a compromise. Two time constants of $I$ and 10 seconds are obtained by switching condensers $C_{1}$ and $C_{2}$ respectively. The necessary voltage to drive the metering circuit is obtained from the range resistors in the plate circuit of $\mathrm{V}-2$. This circuit is essentially a vacuum tube voltmeter using a type CK-526-AX. A four-volt swing of the grid of $\nabla-3$ will give full scale deflection on the 50 microampere ruggedized meter. The grid voltage versus plate current curve is linear over the operation range of grid voltages so that the meter deflection is linear with respect to the voltage developed across any range resistor. Other tubes may be used where higher meter currents are required, as in some applications discussed below. The potentiometer $\mathrm{R}_{2}$ in the cathode circuit, which is controlled externally, serves as zero belance. Zero drift is extremely. small, less than one microampere in 40 hours of operation.

The negative 900 volts for the photomultiplier is supplied by an oscillator high voltage supply with an approximate plate efficiency of 16 percent. The overall efficiency is about 3.5 percent. The relaxation 
oscillator (approximately $100 \mathrm{cps}$ ) triggers the grid of $\nabla-4$. The reactive voltage developed by the choke in the plate of $V-4$ is rectified by $V-5$ and regulated by $V-6$. This voltage is sensitive to oscillator frequency which drifts as the battery supply fades. The frequency is set slightly above the optimum point which gives a peak to be reached and traversed during the useful life of the "B" batteries. This in turn gives constant voltage for a longer time per battery change. Additional compensation is afforded by feed-back of the change of voltage with load at the regulator tube through $R_{2}$ to the grid of $V-4$. The selection of chokes for the high voltage supply is also very Important. Only two reactors of a group tested, the UTC had sufficient positive impedance. The resistive and hysteresis loss in other chokes tested was excessive. The use of a ruggedized meter may be thought extravagant by economyminded constructors, but we have found through experience that meter damage is a major item of service on instmuments of this general size and shape. TaIl, narrow instruments such as these (fig. I) are easily knocked over, with obvious consequences for the meter.

The heart of the portable scintillation counter is the sensitive element, a thallium-activated sodium iodide crystal and photomultiplier tube. The thallium content of the crystal is about I percent by weight. Approximately 25 percent of the garma rays from Ra produce sufficient light in a $1 \times 1 \frac{1}{4}$ inch crystal to be detected by the circuit with a photomultiplier tube of minimum acceptable sensitivity. The type 6199, although far from ideal for this application, was used because it was the only small window ( $1.5 \mathrm{in}$. dia.) tube available when the instrument was designed. This tube is often microphonic, and sometimes exhibits two stable states of operation, apparently related to the 
physinal position of the dynode structure in respect to the cathode at fixed dynode roltage. A silght jarring will cause the tube to "jump" from one stable state to another. With dynode voltage held constant, the sensitivity varies over a wide range. Selection of tubes from conmercial runs is essential. On the average, about one out of four tubes cas be used in this instrument. The tubes tested in our laboratory exhibit a irend in sensitivity that can be associated with physical dimensions. The more sensitive tubes are usually shorter in length. The new type 6291 , is not micropionis in ordinary handling, has exceptional gain and is reiatively uniform in sensitivity (factor of 4 in 7 tubes tested). Unfortunately, the nesessary overall operating voltage of 1200 volts is somewhat high for portable instruments. Much of the difficulty with photomultipliers may be sircumvented by operating each tube at ilis best roltage. When the regulator tube $(\nabla-6)$ is matched to the photomultiplier, the sensitivity will be much more uniform. However, conmer voltage. Regrilatsms with a spread of poltages (900 to 1050 volts) can be obtained on special request and make possible the selection of the proper regulator for the individual phototube being used. The matching prosedure makes it possible to use some photomultipliers otherwise discarded, but greatiy compllates servicing.

Pulses of ald amplitudes come from the photomultiplier. They are roughily Iinear with the energy dissipated in the crystal, up to a point of saturation. The lower limit for pulses that are detected by the amplifier is usualiy d etermined by the ultimate input sensitivity of the circuif ratiex than the background noise of the photomultiplier. Very fine pulse height discrimination is common practice in the laboratory, 
but is difficut to achiere in a simple portable instrument with any degree of reproäueibility.

\section{CALIBRATION}

Ir principle, the absolute calibration of a seintillation counter is no differes: from the same procedure for a Geiger. Min instrument is brought into a known flux of gamma radiation, usually from a radium needie, and the aircuit is adjusted to give the correct reading in milistoentyexs per hour. If all instruments are correctly calibrated, their independent readings can be compared directly, regardless of the spectrum of the source of the garma rays measured, and the intensity will be in milliroentgens per hour if the sourae is radium.

In practic, however, paricus difficulties come up. Our instrument is alibrated by first flight quanta from an effective point source. Scattered radiation is measured separately and is subtracted from the gross intensitgo. In nature, the source is almost always extended, and much of the radiation reaching the detector has been scattered, so that the effeetive spectrum is greatiy enriched on the soft end.

The GaM countem is not particularly sensitive to soft radiation, and a poirt-source calibration is reasonably adequate. The scintillation counter, howewer, has good sensitivity down to wery low energies and most of the scatitered radiation is detected. Consequently, the portable scintiliation counters calibrated with a point-source will not show the right intensity (in milliroentgens per hour) when the measured radiation is seattered. The gross readings are still comparable from countert to counter, but the units are essentially meaningless in practice. 
The secord difficulty in wholesale calibration arises from the great variation in photomaltipliers and the consequent wide variation in sensitivity of the suintillation counters. Given a group of instruments, one has the altemative of either tailoring each circuit to fit the particular photomitiplier or calibrating all instruments at the sensitirity level of the worst one in the group. The first alternative is prohibitive in cost, and the second tends to remove the greatest adrantage of the saintillation counter, its high sensitivity. It has been our experierse inat geologists prefer to have theiro instruments adjusted for optimum sensitivity, at the expense of absolute calibration. It is too early to say whether future experience will modify this wiew.

The thirred probiem is due to the nonlinearity of the circuit at very high counting zates. Even with a dead time of only about fifteen microseconds, colnoidense loss is high at the rates that are observed in some phases of geophysical exploration, particulkrly undr rground. We see no simple way of greatiy reducing the dead time of the clrcuit. G-M counters should be used. where the intensity is too high for linear operation of the seintillation counter.

The stability of the pulse height acceptance level of this circuit is considerably better than one normally expects from portable equipment. This stability is achiered by suitably matching the various batteries and their Ioads so that bias on the grid of V-2 decreases as the plate voltage decreases with aging batteries. In addition, the oscillator may be adjusted to a frequency higher than the optimum. Thus, the voltage on the photomultiplier increases with aging batteries, with the net result of stable orerall sensitivity. Specifications require that one calibration adjustment be sufficient to keep the sensitivity within 10 
percent of the original value for a period of 25 eight-hour days (at constant temperature).

\section{SPECTROMETRY}

It is irequently suggested that portable scintillation counters be used as spectrometers to identify the radiation source by the energy of its gammats (Pringle et al. 1550, and others). We have found that interest in this application is largely academis. It is true that $a$ portable sulntillation eounter covid distinguish between uranium, thorium, ard potassium under specially favorable conditions. However, the required source concentration is so high that almost any geologist can identify the mirieral lorig before he has assembled enough of it for a spectrometric examination. For some of the rarer thorium-uranium minerels, a visual estimate of the thorium-uranium ratio may not be possible. The physical determination of this quantity is difficult even with fairly complete equipment in the laboratory (Peirson, 1951; Eichholz, et al., 1953) and one shoula not expect too much from portable equipment.

\section{SPECTAL APPLICATIONS}

The scintillation counter described here can be used in automobiles and small aireraft without modification. The sensitivity is entirely adequate for these purposes. A more elaborate version constructed in our laboratory wses crystals two inches in diameter to increase the sensitivity. For use on automobiles, the detectors are shielded with $1 / 2$ inch of lead to improve directional sensitivity toward the sides. A detector is mounted on each side of the roof of a car (fig. 4) and 


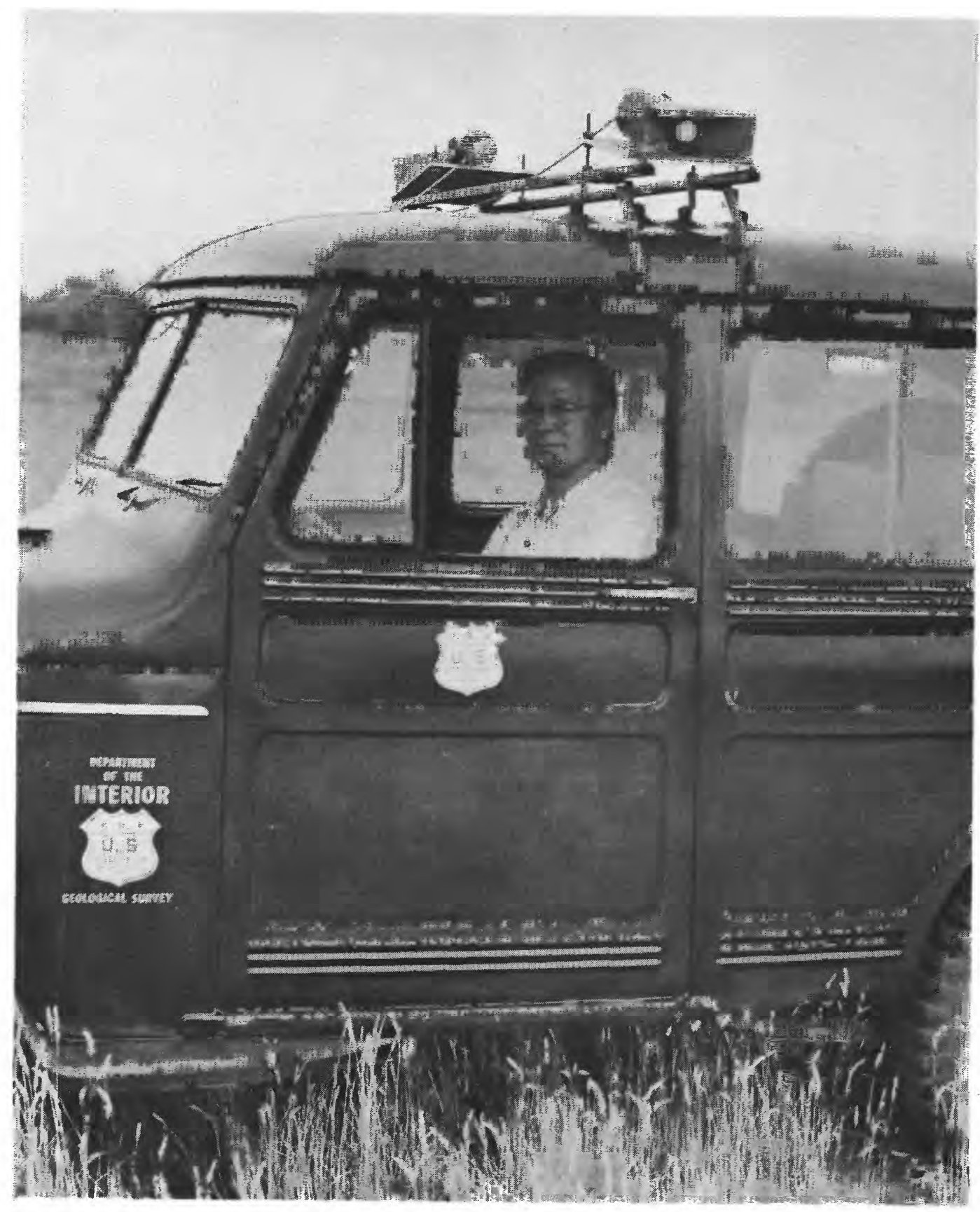

Figure 4. Car-mounted twin scintillation heads, shielded with lead for directional search. 
the output of both photomultipliers is fed into a circuit very similar to that shown in figure 3, except that the output tube is a typo CX:40t $\mathrm{AX}$ which has sufficient power to drive a strip chart recording milliammeter. A switch permits the use of one or both of the detectors to facilitate directionel searching.

The same basic circuit also has been modified for gamm-ray logging of holes as deep as 1,000 feet ( $f$ ig. 5). Whenever it is necessary to transmit pulses over cables even just a few feet long, a matching circuit of the type shown in figure 6 is found useful. The logging probe contains a photomultiplier with a small crystal and the matching circuit. A similar circuit precedes the input in the surface instrument which is identical to the carborne or airborne unit discussed earlier.

When it is necessary to feed more than one photomultiplier into the circuit shown in figure 3 with matching circuits in between, special care must be taken to separate the input channels or amplify the signals prior to combining them. Transtistor networks are very useful for this purpose. If the channels are not separated, some of the signal from one detector will be dissipated in the matching networks of the other(s) with the consequence of impaired orerall efficiency.

\section{FUTURE DEVELOFMINTS}

It is not likely that the size and weight of the present instrument can be radically reduced by future design. It is hoped, however, to improve stability and reproducibility to a point where the instrument can be calibrated in absolute units and can be used for accurate surveys.

A new design has been "on the boards" for about a year and is now reaching the prototype stage (fig. 7). The new instrument use the saine high 


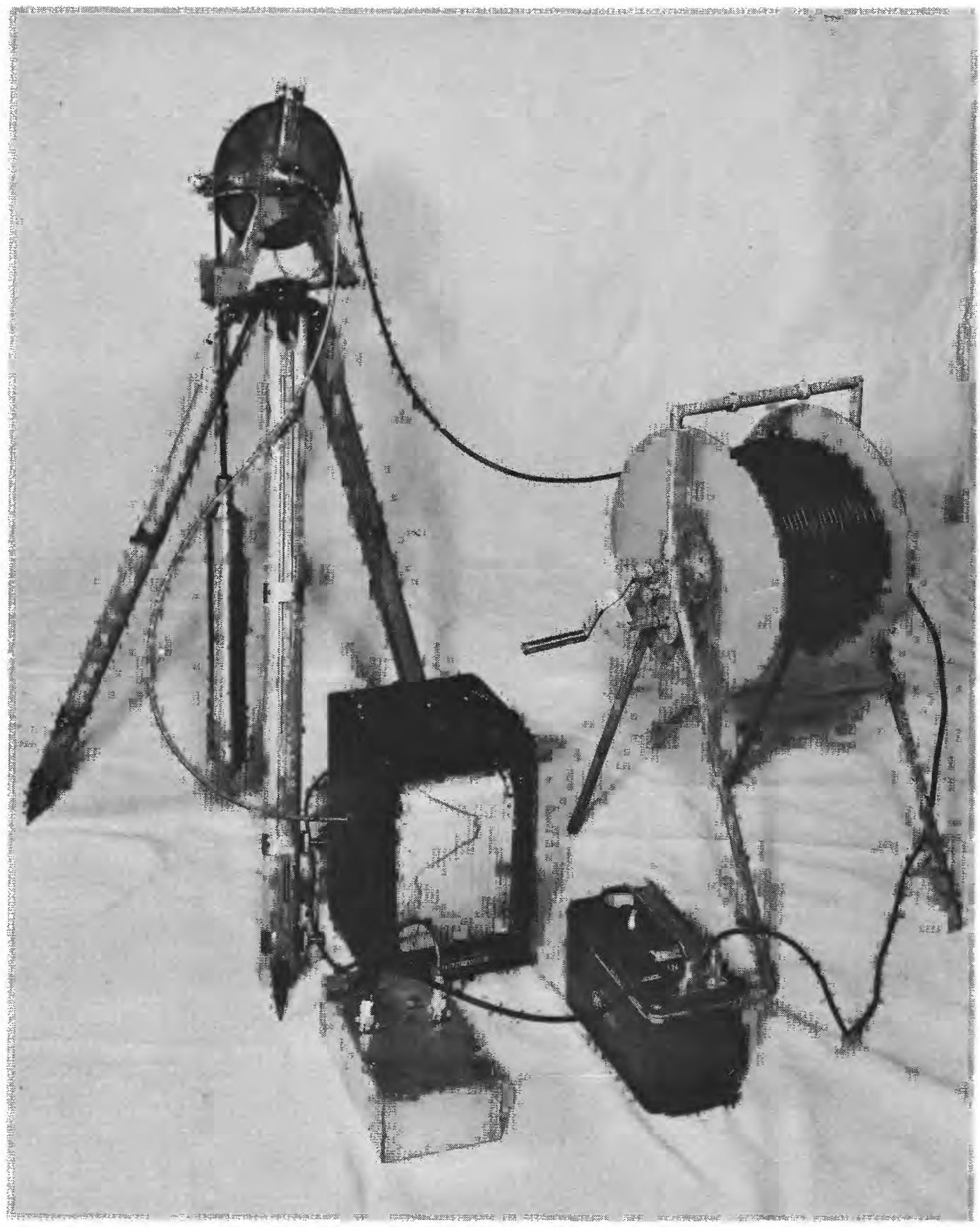

Figure 5. Scintillation logging equipment, showing probe, reel with 1000 feet of cable, ratemeter, vacuumtube voltmeter, current amplifier, and strip-chart recorder. The voltmeter and recorder can be omitted for logging of holes in remote areas where transport is a problen. 


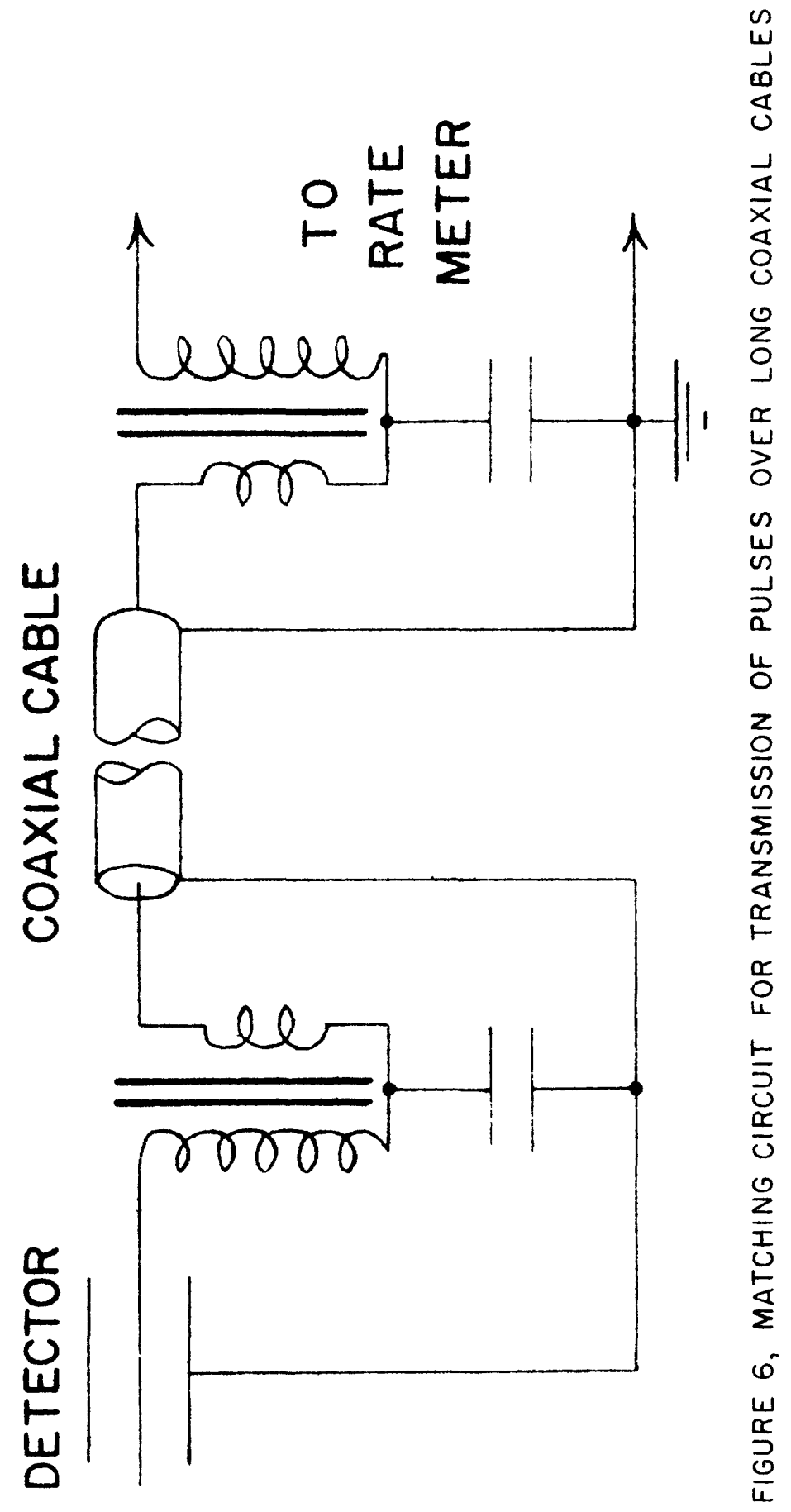




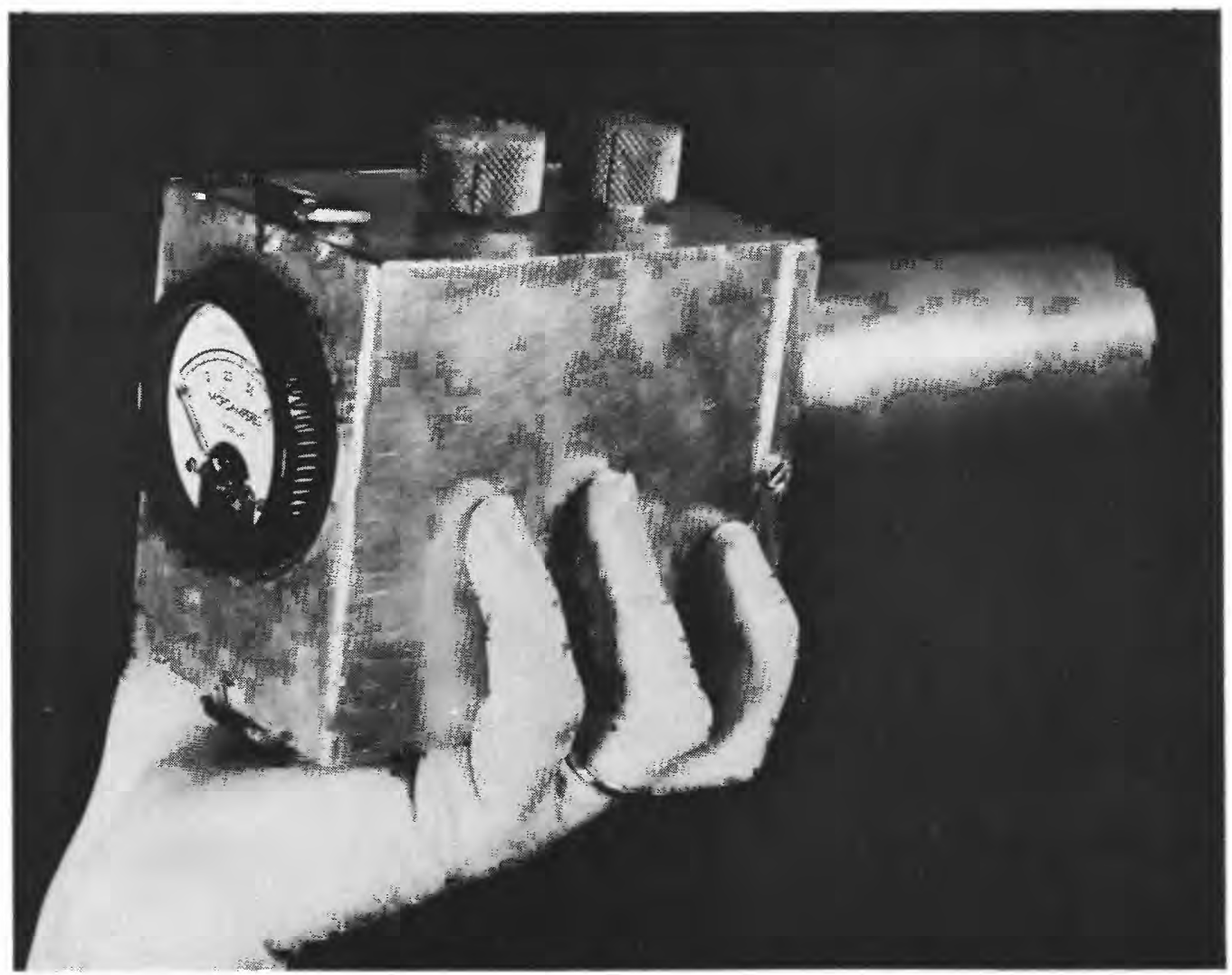

Figure 7. Experimental model of the integrating (total intensity) scintillation meter. 
voltage supply, but the counting circuit is greatly simplified. This circuit does not "count" pulses, but, in effect, measures the total intensity of light emitted by the crystal. Since the amount of light is a function of both the number and the energy of the incident gamma rays, the meter reading of this instrument will indicate more nearly the "total dosage rate" rather than the number of disintegrations of a source of radiation.

The circuit ( $f i g \circ 8$ ) is essentially a D.C. amplifier, biased to projected cut-off。 The meter is in series with the plate and is mechanically set to read zero when about three microamperes of plate current flow. Bias is applied to the cathode by means of a bleeder network. The screen is supplied by a separate 22.5 -volt battery connected directly between screen and cathode. This arrangement prevents the falling off of screen voltage which would result in non-linear response of the meter if the screen were fed by means of a droppịng resistor or bleeder from $B+$. The signal is applied directly to the grid from dynode No. 10, as a positive valtage is required, and the sensitivity is controlled by the amount of resistance in this circuit. Barlier experimental measurements with this type of circuit showed rather large and frequent upswings of the meter while measuring relatively low background radiation. These upswings are attributable to large pulses, from ten to thirty volts in amplitude caused by cosmic showers, whereas the average pulse from radium has a peak value of about two voltb. The effect of these extremely large pulses is reduced in this circuit, because any pulse greater than about 2.5 volts in amplitude drives the grid positive in respect to the cathode and is clipped in the grid circuit. In addition, the flow of 


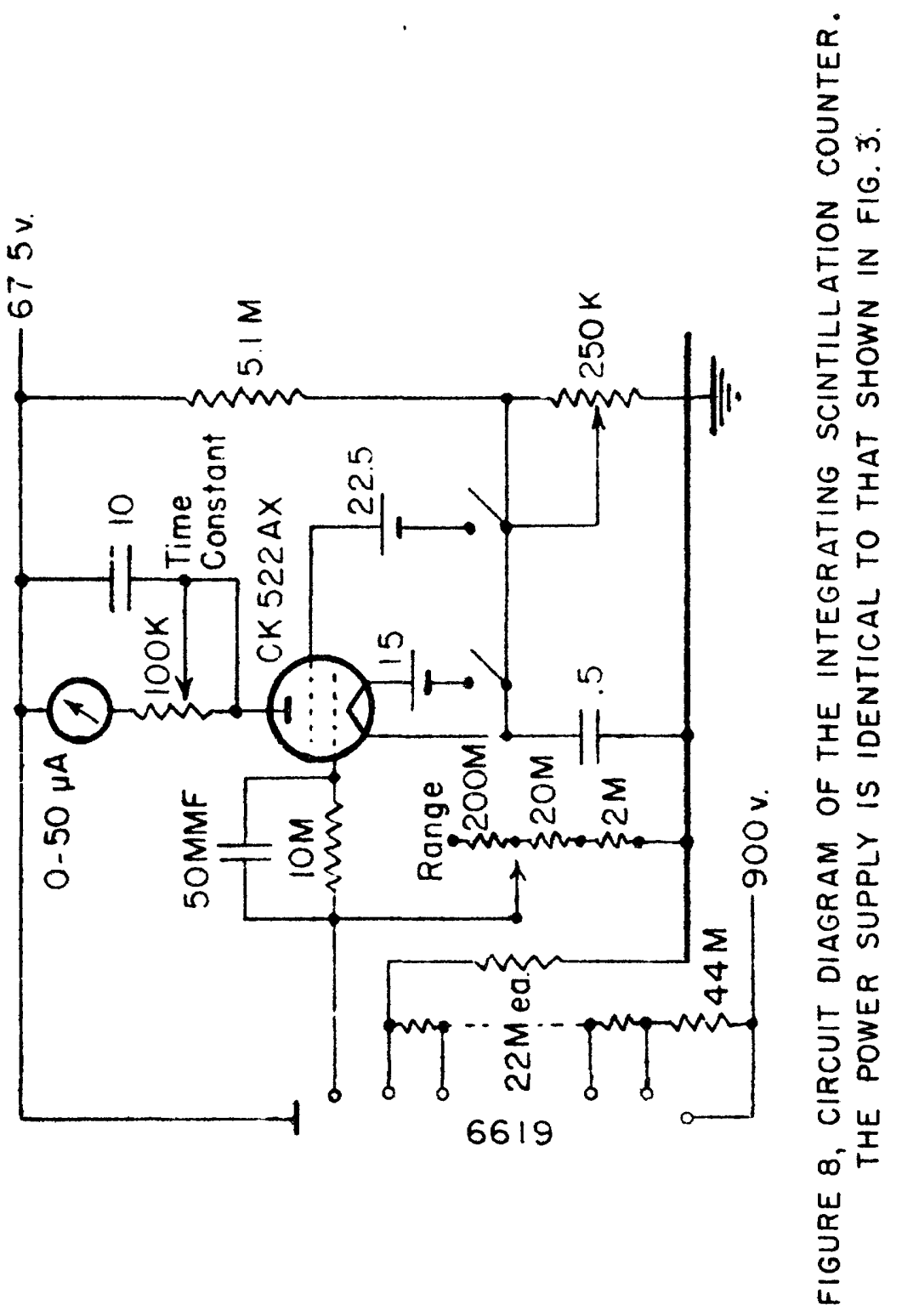


grid current thus caused develops a bias pulse across the 10 megohm grid leak - 50 micromicrofarad condenser combination to counteract the effect of the large pulse on plate current.

A potentially useful feature of this integrating instrument is the continuously variable time constant of the meter circuit. By adjusting the 100,000 ohms potentiometer in series with the meter, the response time (and therefore the flutter) of the meter can be made to have any value that the particular situation demands.

The complete unit, including batteries, is now contained in a case $4 \times 41 / 2 \times 3$ inches, with a probe 2 inches in diameter projecting $51 / 2$ inches from the front (fig. 7). The meter is mounted in the back of the case. The total weight of the preliminary model is less than $31 / 2$ pounds, and it has a battery life of nearly 200 hours. Bench tests show negligible drift in zero and sensitivity throughout the life of the batteries.

There are definite drawbacks to this circuit in its present form. Only the best of photomultipliers will work satisfactorily; most have insufficient gain at 900 volts; some have too much dark current; some have internal leakage which affects the zero adjustment. The dark current sets a lower limit to the useful response of the instrument. A larger crystal will help solve this difficulty, but the weight and cost of the crystal becomes an item to be considered in the design of a small instrument. The high value of range resistors (200 megohms on the most sensitive range) may make the reading sensitive to humidity changes. It is not known how this instrument will compare in the field with those already in use and described in the earlier parts of this paper. Because the 
meter indication depends as much on energy as it does on the number of disintegrations, it is possible that this instrument will not show as good a response to weak anomalies in the field as the instruments now in use. The great advantages of small size and weight and slightly lower construction cost may overbalance the obvious shortcomings of the circuit. Extensive testing, now in progress, will be required before the usefulness of the design can be determined.

\section{A CKNOWLEDGMENTS}

We are greatly indebted to our colleagues at the Oak Ridge National Laboratory and Los Alamos Scientific Laboratory. for their kind and helpful assistance during the early phases of this work. Particular thanks are due Messrs. Co J。 Borkowsky, Ray Dandl, Ro Jo Watts, and F。 Jo Davis, Dra Hugh Carmichael of the Chalk River laboratory and Mr. John Harshaw of Harshaw Chemical Company have been very helpful in discussions of the various techniques of crystal mounting. We are grateful to the many geologists and engineers who have helped us in the practical field evaluation of this instrument and whose patience and goodwill we so frequently strained. The work here reported is part of a program that the U. S. Geological Survey is conducting on behalf of the Division of Raw Materials of the U. So Atomic Energy Commission.

\section{EITERATURE CITED}

Brownell, Go Mog 1950, Radiation surveys with a scintillation counter: Econ。Geology, v. 45, p. 167-174。

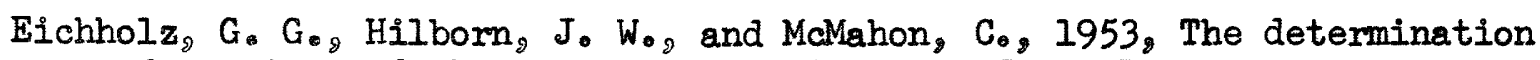
of uranium and thorium in ores: Canadian Jotar. Physics, V. 3l, $p .613-628$. 
Faul, Henry, 1948, Radioactivity exploration with Geiger counters: Am. Inst. Min. Metal Eng. Trans。, vo 178, po 458-478。

-1950, Radioactivity methods: Chapo X, p. 987-1015, in Jakosky, J。J.g Exploration geophysics, Trija Publishing Company, Los Angeles。

Nelson, J. M. 1953 , Prospecting for uranium with car-mounted equipment: U. So Geol。 Survey Bull。 988-I.

Peirson, DoH., 195I, Alpha particle assay and the measurement of the thorium-uranium ratio in radioactive ores: Phys.Soc。London Proc。 B., v. 64, 876-888.

Pringle, Ro Wo, Roulston, K. Io, and Brownell, G. M., 1950, Ultra-sensitive portable gamma-ray spectrometer: Nature, v. 165, p. 527.

Rajewsky, B., Das Geiger-Muller-Zahlrohr im Dienste des Bergbaues (The G-M counter applied to mining): Zeitschro. Physik, v. 120, p. 627-638.

Ridland, G。 Co, 1945, Use of the Geiger-Mueller counter in the search for pitchblende-bearing veins at Great Bear Lake, Canada: Am. Inst. Min. Metall. Eng. Trans., v. 164, p. 117-124.

Schmitt, O. H., 1938, Thermionic trigger: Jour. Sci. Instruments, v。 15, p. 24-26.

Slack, H. A。, 1949, Radiaactivity measurements in the Kirkland Lake area, northern Ontario: Am. Geophys. Union Trans., v. 30, p. 867-8740

Slack, Ho Ao and Whitham, $\mathrm{K}_{0-9}$ 19.51, A further investigation of the radioactivity of the Round Lake and. Elzevir batholiths: Am. Geophys. Union Trans., v. 32, p. 44-48. 